\title{
Processos distroficos na molestia de Carlos Chagas \\ pelo
}

\author{
Dr. LEOCADIO CHAVES
}

Membro da Comissão para o estudo da molestia de Chagas

\begin{abstract}
A investigação clinica, a mais superficial, demonstra que nas rejiões flajeladas pela molestia de CHAGAS existem em forte proporção individuos afetados de distrofias variadas, entre as quais avultam pela sua maior frequencia as que se caraterisam por perturbaçōes do desenvolvimento geral. Aì são encontradas, a cada passo, crianças retardadas, mixedematosas, pseudocretinas, etc., além de outras manifestações da mesma natureza, limitadas e certos organs ou sistemas, taes como distrofias osseas, musculares, cutaneas, etc., que serão mencionadas no correr deste trabalho.
\end{abstract}

A presença de taes distrofias em zonas sob o dominio da endemia de CHAGAS sujere forçosamente a necessidade de se verificar se elas têm alguma relação com a referida endemia, ou por outra, se devem ser consideradas como modalidades da molestia reinante.

A solução deste problema constituiu uma das preocupações da comissão, que sob a direçâo do Instituto Oswaldo Cruz foi encarregada de investigar in loco a epidemiolojia da nova entidade morbida e estabelecer bases de sua profilaxia. Os estudos realisados com tal intuito trouxeram dados a nosso ver suficientes para antorizarem resposta afirmativa á tese proposta. Para certo numero de casos em questão, a verificaçảo de sua orijem tripanosomica evidenciou-se positiva. Taes foram as distrofias ligadas ás formas nervosas daquela molestia, forma de diagnostico indubitavel e nas quais fica tambem indubitaveh a subordinação das referidas distrofias á mesma etiolojia. Para outro grupo de casos, porém, essa demonstração etiolojica tem sido embaraçada de um lado, pela falta de autopsias de formas puras de tais distrofias, do outro lado, pelas dificuldades geralmente encontradas na verificação do Trypanosoma cruzi, durante a vida, nos estados cronicos de suas manifestações morbidas. Esse grupo é constituido por varios processos distroficos cuja patojenia é explicada por perturbaçõ ess endocrinicas, sobretudo por aqueles que dependem de alterações da glandula tireoide e que formam vasta endemia comparavel ao cretinismo endemico, do qual tem os principais elementos constitutivos, inclusive sua associação ao bocio. A filiação desta endemia á tripanosomiase de CHAGAS 
é, entretanto, realisavel mediante certo numero de dados, dos quaes alguns merecem aqui referencia pormenorisada.

A coincidencia de sua distribuição geografica com a das outras fórmas da molestia de CHAGAS, e, respetivamente, com a do iransmissor desta molestia, é fato bastante demonstrativo sob este ponto de vista. Essa coincidencia, segundo as observações feitas até o presente, não pode ser contestada e foi revelada em todos os pontos que se têm visitado com o intuito de verifical-a. Pode-se afirmar que no Brazil, onde quer que se tenha observado, sob a forma endemica, a presença das mencionadas distrofias, é certa a coexistencia de outras modalidades daquela molestia, de caraterização inconcussa e, o que é tambem importante, quasi sempre associadas no mesmo doente, constituindo o tipo clinico complexo, que é o mais frequente e de maior evidencia na nosografia das rejiões atacadas.

Por outro lado, têm sido infrutiferas todas as investigações feitas para encontrarse nas zonas da endemia outras causas, que não a tripanosomiase, ás quaes se possa atribuir o aparecimento desses estados distroficos. A presença destes ultimos, assim como das outras formas da tripanosomiase verificase em extensa rejião, que abranje a maior parte do planalto central do Brazil e algumas zonas limitrofes, com maior intensidade nos Estados de Minas Geraes, Goyaz e S. Paulo. Ai, a manifestação dessa entidade morbida só cessa nos pontos em que, por condições desfavoraveis do meio, cieixam de proliferar as especies de Triatoma hospedeiras e transmissoras do Trypanosoma cruzi. Este é o unico fator etiolojico permanente ou constante, responsabilisavel nessas reiiões pela presença de taes entidades.

A outros ajentes infeciosos e toxicos ai tambem encontrados, não se pode conferir o mesmo papel patojenico pelo simples fato de sua discontinuidade topografica. Nestas condições então o impaludismo e o anquilostomiase, as duas endemias que depois da tripanosomiase se apresentam em maior extensão territorial e cujo aparecimento não se verifica em localidades devastadas por esta molestia. Pode-se dizer da sifilis que e sua raridade exclue qualquer idea de participação na constituição da endemia.

O mesmo deve ser afirmado das causas locaes, a agua e a natureza do solo, por muitos patolojistas consideradas como determinantes da dejsneração cretinica endemica, cuja semelhança com as distrofias em questão foi acima mencionada. Para esta ultimas a Territoriale Noxe dos autores alemães introduzida no organismo humano pela agua de alimentação, orijinaria de certas formações geolojicas, parece não ter a pretendida significação etiolojica, que refutam cabalmente os dados tirados da epidemiolojia ciessas distrofias e os conhecimentos existentes sobre sua localização nos diferentes sistemas do solo brazileiro.

Segundo H. BIRCHER, o mais genuino representante da escola que patrocina a orijem hidro-telurica da endemia bocio-cretinica, esta só se manifesta nas rejiões formadas pelos sedimentos maritimos da idade paleozoica (silurianos, devonianos, carboniferos), o do periodo triassico e da idade terciaria. Deixando de lado as contestações que têm sido feitas por muitos patolojistas a esse modo de pensar, no Brazil, essa dependencia não encontra confirmação, porquanto a endemia brazileira se verifica em grande parte, senão em sua maior ex!ensão topografica, sobre terrenos outros que não os acima apontados como fatores indispensaveis para a existencia da endemia européa. Assim, os afetados pelas referidas distrofias são encontrados não só em terrenos paleozoicos e miocenos (parte do vale do rio S. Francisco) como nos terrenos arqueanos que formam o complexo geolojico de grande parte do pla. nalto central do Brazil, emquanto que se mostram indenes os sedimentos terciarios existentes ao longo do litoral.

São tambem aplicaveis a essa demonstração os dados existaittes sobre a epidemiolojia do bocio qua sob a fórma endemica acompanha taes estados distroficos e a ctijos fatores etiolojicos se acha intimamente ligado.

Varios desses dados foram apresentadus 
pelo Dr. CARLOS CHAGAS em seu trabatho de sintese sobre a tripanosomiase americana publicado em 1911 (Memorias do Instituto Oswaldo Cruz, tomo III). Por eles pode-se chegar à conclusão de que a orijem hidrica não é admissivel para o bocio endemico brazileiro. Numerosas observações de pessoas estranhas ás rejiôes em que ele se manifesta e que ai têm habitado muitos anos, fazendo uso das aguas presumidas bocijenas, sem se mostrarem afetadas. confirmam essa asserção, e mais convincentes se tornam pelo fato de ser empregada no caso como unica medida profilatica especial a proteção contra a picada da Triatoma inoculadora do Trypanosoma cruzi.

A essas observações vieram juntar-se muitas feitas posteriormente sempre confirmadoras, das quais resalta igualmente $o$ papel da tripanosomiase na produção desse elemento morbido. Elas demonstram que em todas as cidades ou povoações, nas quais a construção das casas obedeceu a certas regras de hijiene, sendo o meio improprio á vida dos hematofagos transmissores daquela molestia, verifica-se com a ausencia destes ultimos a ausencia não só do bocio como dos estados distroficos que os acompanham.

Além disto, em geral, as cidades ou povoações indenes de bocio nas rejiões por este contaminadas não dispõem de canalização de agua potavel e a agua consumida por sua população não é, quanto á sua orijem telurica, diferente da que abastece a população rural circumvizinha fortemente atacada.

E' sabido que entre as especies infetantes de Triatoma, as domesticas representam a principal função senão exclusiva na transmissão humana da molestia d $\epsilon$ CHAOAS e que sua presença só é habitual nas babitações primitivas, usadas no interior do paiz com o nome de cafúas, cujas coberturas e paredes thes oferecem babitat muito apropriado. E' justamente nestas habitações infestadas pelas triatomas que se observam, geralmente, os estados morbidos a que nos referimos, emquanto que as casas bem construidas, nas quais raramente e só de modo acidental podem ser encontrados esses hemipteros, mostram-se livres de taes manifestações. Este fato se expressa de maneira muito significativa em povoações intensamente infestadas, nas quaes domicilios aproximados abrigam pessoas doentes ou sãs onnforme as condições de sua construção e a presença ou ausencia de triatomas.

Os dados acima mencionados tirados da epidemiolojia são confirmados pela histo-patolojia geral da tripanosomiase. As alterações locaes produzidas pelo Trypanosoma cruzi se traduzem por duas ordens de fatos altamente carateristicos que são, na ordem de sua evolução: a localização do protozoario no interior dos elementos nobres dos organs e a reação inflamatoria consecutiva que visa a defeza do tecido atacado. $O$ primeiro tem como uma das consequencias frequentes a destruição das celulas parasitadas; o segundo desenvolve-se em torno destas celulas com afluxo de linfócitos e hiperplasia do tecido conjuntivo intersticial, que se pode tornar definitiva e determina estado cirrotico mais ou menos acentuado. Algumas vezes, a reação local se manifesta tambem pela proliferação do proprio parénquima, traduzindo ação rejenerativa ou tendo por fim compensação funcional que, em determinadas circunstancias, chega a se transformar em hiperfunção. Outras vezes, taes modificações histolojicas se apresentam sem a presença dos parasitos; nota-se, somente, em pequeno numero ou fortemente difundidos no orgam lesado fócos de infiltração linfocitaria e de hiperplasia conjuntiva, que representam pontos de localisação parasitaria que a reação local conseguiu dominar. Estas lesões em fóco, sem tripanosomos podem ser consideradas especificas nos casos em que, sendo negativa a verificação do protozoario, a sintomatolojia e a epidemiolojia falam a favor da tripanosomiase.

Além dos fenomenos locaes, resultantes diretamente da presença do tripanosomo, notam-se ainda aiterações dejenerativas que parecem ser exclusivamente de orijem toxica (dejeneração gordurosa do figado). 
As lesões histolojicas, que resumidamente descrevemos, que se localisam em organs, cujo funcionamento é indispensavel ao equilibrio nutritivo, taes como as glandulas de secreção interna e o sistema nervoso central, explicam a possibilidade de manifestações de carater distrofico na tripanosomiase de CHAGAS. Nas fórmas agudas desta infeção, a presença de taes lesões é a regra; nas fórmas cronicas, seja que elas sucedam á fase aguda da molestia, ou que assim se instalem desde o inicio, elas têm sido verificadas frequentemente pelos exames histo-patolojicos que vêm confirmar sinais clinicos observados durante a vida (sindromes glandulares, distrofias nervosas).

Entre os estados distroficos existentes nas rejiões flajeladas pela molestia de $\mathrm{CHA}$ GAS, avultam por sua preponderancia numerica aqueles que devem seu aparecimento ás perturbaçōes funcionaes oriundas de lesões da glandula tireoide, lesões, cuja constancia naquela molestia já the valera a denominade tireoidite parasitaria. Em virtude da grande frequencia e da importancia que estes estados asșumem no quadro nosolojico das referidas rejiōes, justifica-se em estudo de conjunto a especificação de todas as manifestações distroficas em dois grupos distintos: distrofias de orijem tireoidiana e distrofias de orijem outra que não a glandula tireoide.

\section{Distrofias tireoidianas.}

Sua orijem é demonstrada pela sintomatolojia que reproduz o quadro classico da insuficiencia tireoidiana em varias de suas gradações, e pela eficacia comprovada da opoterapia especifica sobre a totalidade dos sintomas que the são peculiares ou apenas sobre alguns desses sintomas, quando os doentes já atinjiram a certo grau de désenvolvimento. Em alguns casos, nos quaes foi possivel executar-se a reação de ABDERHALDEN ficou tambem evidenciada a mesma influencia patojenica.

No ponto de "vista da frequencia, elas apresentam coeficiente muito elevado, não só em relação aos processos distroficos de causa diversa, como em relação a outras mani- festações da tripanosomiase de CHAGAS, consideradas isoladamente. Pode-se mesmo afirmar serem raros os naturaes nas zonas contaminadas por esta molestia que não mostrem sinaes de lesão da tireoide, quasi sempre decorrentes de insuficiencia funcional deste orgam. $O$ hipotireoidismo constitue assim condição morbida que domina a nosografia rejional como elemento de associação e agravação de todas as molestias reinantes.

Tal frequencia, entretanto, não resulta somente da constancia, com que a glandula tireoide é afetada pelo processo infecioso, mas, tambem, das condições de seu desenvolvimento epidemico. Nas infeções agudas o ataque á tireoide nunca falhou nos casos até agora observados e revela-se, clinicamente, pelo mixedema generalisado, que indica estado de hipofunção glandular; histolojicamente, pelas lesões organicas acima mencionadas, sem mesmo faltar o parasito no interior das celulas. Nas infeções cronicas consecutivas á fase aguda da molestia, as lesões tì eoidianas persistentes dão logar a varias distrofias, do mesmo modo por que a persistencia das lesões identicas no coração e no sistema nervoso central determinam as formas cronicas da tripanosomiase, cardiaca e ner-

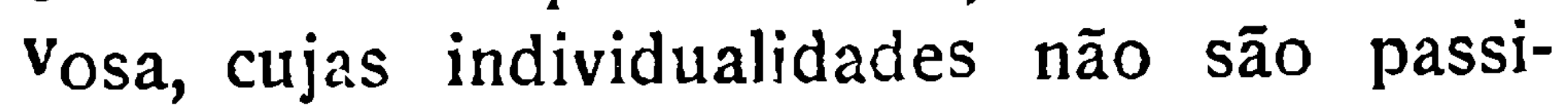
veis de contestação. Tambem, não deve ser diverso o mecanismo nos doentes em que a infeção se estabelece silenciosamente $e$ evolve com a marcha cronica, desde o inicio.

No que respeita ao desenvolvimento epidemico, os estudos feitos demonstram que os ajentes transmissores da molestia de CHAGAS, isto é, as especies infetantes de triatoma, infestam numero tão grande de habitações e nelas existem em tão grande quantidade, que, salvo o caso de transmissão hereditaria, se torna muito dificil, senão impossivel aos habitantes nacidos na rejião escapar á infeção, nc primeiro ano de vida. Nesta epoca, a molestia se manilesta quasi sempre sob a forma aguda que tem como carateristica"mais constante o ataque á glandula tireoide. A lesão deste orgam em fase da vida em que o desenvolvimento individual faz mais necessario seu influxo funcional, 
exalta a frequencia dos processos distroficos consequentes e explica tambem o determinismo de algumas formas clinicas, que ficam na dependencia da idare, em que se inicia $o$ processo infecioso, assim como da persistencia e da intensidade das alterações tireoidianas.

Dissemos acima que nas infeções agudas pelo Trypanosoma cruzi o mixedema é sintoma infalivel. Ele pode ser considerado como o processo distrofico inicial da molestia, caraterisado por infiltração do tecido ceJular, pela mucina, que resulta de dejeneração protoplasmica consecutiva a perturbações de ordem trofica. Além do mixedema das infeções agudas, que se distingue tambem por sua aparição quasi subitanea (alguns dias após o inicio da febre) rejistam-se outras distrofias tireoidianas, atribuiveis á endemia de CHAGAS, de que constituem, em geral, elementos seriados.

São elas o hipotireoidismo infantil, o infantilismo, o cretinismo e o hipotireoidismo do adulto aos quais se associa como manifestação de etiolojia similar o bocio endernico.

Hipotireoidismo infantil: De todas as formas é a que mais expressa a infeção ainda em atividade e sucede frequentemente ao periocio agudo da molestia, da qual apresenta quasi sempre sequelas de valor para o diagnostico. Assim, o mixedema, que, anteriormente, por sua intensidade se impunha á propria observação familiar, não desapareee de todo, persistindo mais ou menos diminuido com a difusão primitiva ou apenas localizado em certas rejiões, de preferencia na face, dando-Jhe aspetc tumido carateristico; a hepato e a esplenomegalia, a hipertrofia ganglionar, sinais igualmente constantes no mesmo periodo continuam, posto que reduzidos, atestando a natureza de sua etiolojia. Para o lado da tireoide, as alterações são ainda mais persistentes e demonstraveis pelo exame clinico, ao qual este orgam se mostra ora aumentado de volume, ora decrecido e de consistencia anormal, fibro-granuloso ou cistico.

A sindrome apresenta numerosas variações, desde o mais leve atrazo de desen- volvimento individual de carater frustraneo, até as fórmas bem acentuadas, como as perturbaçôes especificas da péle e dos anexos, do esqueleto, da intelijencia etc., não raro com franca infiltração mixedematosa sem nunca atinjir, porém, ao gráu de intensidade que caraterisa a caquexia paquidermica de CHARCOT. De fato, este estado distrofico se distingue pela relativa benignidade da generalidade dos casos, que constituida em sua maioria por crianças levemente retardadas, total ou parcialmente, em varios sistemas organicos e funçōes psiquicas. Essa benignidade traduz alterações anatomicas lijeiras do orgam tireoidiano, que podem ser reparadas ou pelo menos compensadas, permitindo a regressão dos sinais morbidos existentes e restituição do individuo ao tipo anatomo-fisiolojico normal ou quasi normal. Tal regressão, que se nota tambem, ainda que raramente e em grao pouco acentuado nas sindromes nervosas da tripanosomiase, não cunstitue ocorrencia rara e contrasta com a ausencia absoluta de casos em que a gravidade dos sintomas demonstra privação conıpleta do funcionamento da tireoide, por falta conjenita ou inutilização deste orgam na vida extra-uterina.

Com a ausencia da atireoidia verificada por observação de alguns anos na zona da endemia, deve ser assinalado tambem que os sinais morbidos, pelo menos na maioria dos doentes, parecem consecutivos á infeção contraida depois de nacimento. Em aigumas centenas de crianças, naturaes das rejiōes infetadas, somente em 3 casos pudemos verificar hipertrofia conjenita da tireoide, revelada pela presença do bocio ao nacer, emquanto que a anamnese e a observação demonstram frequentemente que os individuos afetados naceram com aspeto normal e tiveram desenvolvimento regular até a epoca em que uma molestia febril acompanbada de inchação, deu inicio ás alteraçc̃es troficas presentes além de outras manifestações mais positivas da molestia, taes como paralisias diversas, indicadoras de localizações parasitarias no sistema nervoso.

Sendo notorio que o hipotireoidismo é 
condição morbida dominanie entre os habitantes das rẹiões referidas, caus? reparo a raridade dos casos que apresentam desde $o$ nacimento sinaes francos de insuficiencia tireoidiana. O fato é, entretanto, verdadeiro e tem o seu simile no que se passa com $u$ cretinismo endemico, de que são tambem excepcionaes os doentes nacidos já afetados desse estado distrofico para o qual se estabelece como fator etiolojico indispensavel a ação prolongada de certa nocividade territorial que aje em terreno predisposto por hereditariedade. Nas formas do hipotireoidismo endemico brasileiro a transmissão hereditaria é possivel diante da simples consideração de que, como endemia, esse estado morbido existe, ha seculos, e se tem manifestado em gerações sucessivas. Adquirido por infeção tripanosomica, que, como já foi dito, constitue a unica causa local conhecida e podendo atuar de modo prolongado, como todo estado patolojico constitucional, ele não se pode furtar ás leis da hereditariedade. Somente a herança se expressa no caso por simples predisposição morbida, explicavel pela. extrema benignidade das perturbações tireoidianas na generalidade dos individuos com capacidade para a procreação, sendo, por outro lado, improdutivos por inibição da função sexual aqueles, em que essas perturbações se tornam graves e definitivas. A predisposição hereditaria viria então agravar a situação dos infetados pela tripanosomiase e facilitaria a explosão do mixedema generalisado e dos outros sinais de insuficiencia da glandula tireoide que a infeção encontra em estado de mioprajia conjenita.

Infantilismo e cretinismo: A persistencia do hipotireoidismo infantil determina desvio do desenvolvimento psiquico-somatico do doente e conduz ao infantilismo e ao cretinismo. Não obstante, desconliecidas as condições em virtude das quais a insuficiencia glandular se orienta nesse ou noutro sentido, a identidade da etio-patojenia destes dois estados morbidos resalta do fato que a epidemiolojia familiar rejista a cada passo de irmãos que viveram senıpre no mesmo meio e, portanto, sujeitos ás mesmas influencias patojenicas realizarem, uns o tipo infantil, outros o tipo cretino. Deve ser declarado, entretanto, que csses estados distroficos não podem ser bem diferenciados como individualidades clinicas, porquanto, em todos os infantis se verificam sempre sinaes que autorizariam a classifical-os de cretinos, embora na maioria das vezes de forma atenuada, frusta on incompletá. Por isso, a expressão cretinismo é aqui aplicada somente aos casos que apresentam o aspeto classicu desta sindrome com as alterações peculiares para o lado da péle: o espessamiento, coloração ambarina especial, estado rugoso etc., nos quaes os caracteres infantis são apenas parciaes e deixam de se manifestar muitas vezes na esfera sexual.

O tipo genuinamente infantil, como é compreendido pela definição de LASÈGUE, é o mais frequente e apresenta-se á observação conforme o maior ou menor grau de infiltração mixedematosa sob dois aspetos diferentes: magro e o mixedematoso. $\mathrm{O}$ primeiro se aproxima bastante da forma descrita por LORAIN com a denominação de chetivisme, parecendo ter algumas vezes patojenia mixía, na qual ao lado do hipotireoidismo figura a hipoplasia vascular, conjenita ou adquirida, resultante de causas outras infeciosas ou toxicas, entre as quaes devem ser aporitados 0 alcoolismo dos pais, o es $^{-}$ gotamento materno, as molestias intestinaes e a deficiencia de alimentação na primeira infancia. Nestes casos, o elemento mixedema é pouco apreciavel. Por atenuação da insu. ficiencia glandular ou consumido pelas causas referidas de depauperamento, ele dificilmente se revela ao exame clinico; subsiste apenas, em proporções muits reduzidas na face, ou mais raramente nos membros, em um i ou outra rejião do tronco, on não é de todo encontrado. Nota-se, porém, como sinais de sua existencia anterior e de sua absorção certas alterações do revestimento cutaneo que é então frouxo, enjelhado e superabunciante.

Entre o tipo magro e o mixedematoso existem formas de transição, que se mostram tanto menos frequentes, quanto mais se apro- 
ximam deste ultimo. O tipo mixedematoso é realmente raro, porquanto nossas observações rejistam apenas poucos casos que apresentam mixedema bem acentuado para merecerem tal classificação. E' obvio que ele representa processo de maior gravidade e indica lesão organica mais intensa e sua raridade confirma a noção da benignidade relativa da endemia hipotireoidiana.

As formas de transição são tambem assinalaveis entre o infantilismo e o crelinismo propriamente dito, fato que vem provar tambem a identidade da etio-patojenia desses processos distroficos.

Quanto a sintomatolojia, quer o inf intilismo, quer o cretinismo, á parte certas variantes dependentes de qualidades etnicas e de relativa benignidade do processo morbido que serão oportunamente mencionadas, reproduzem de modo geral o quadro descrito pelos observadores europeus. Ha, porém, para eles, assim como para o hipotireoidismo infantil, outros elementos associados que thes dão feição peculiar e muito agravam as condições dos doentes. Taes elementos são representados pelas manifestações da tripanosomiase dependentes das localisações parasitarias no coração e no sistema nervoso central. Estas ultimas se expressam geralmente por diplejias cerebraes, cuja frequencia nas localidades flajeladis por esta infeção, é notavel, e constitue endemia nervosa sem exemplo na geografia medica universal. De orijem tripanosomica bem verificada, elas se associam muitas vezes ás sidromes tireoidianas, de que são o mais importante fator de agravação. Os casos graves de hipotireoidismo são exclusivamente aqueles em que se nota a coexistencia de lesões nervosas e somente das lesões nervosas resulta a idiotia profunda, emquanto que nas formas puras as perturbações mentaes dos doentes são apenas evolutivas; ha na maioria das vezes simples retardamento da intelijencia. As lesões nervosas podem, além disso, modificar a morfolojia destes estados morbidos pelas varias distrofias delas resultantes, taes como, atrofias musculares, aeformaçōes osseas, craneanas etc. A complicação cardiaca é representada por miocar- dite especifica, de evolução cronica, que geralmente atinje á evidencia clinica completa em idades mais avançadas, de modo que se torna nela sua intervenção como modificador morfolojico das sindromes. Na evolução clinica destes dois processos distroficos tambem se nota, algumas vezes, alterações caraterisadas por atenuação das sindromes, que podem ir até a regressão quasi total ou parcial dos mesmos, fato que parece depender não somente da diminuição da lesão tireoidiana, mas tambem da maior ou menor intersidade do influxo glandular, por parte do organismo, variavel conforme certas condições de idade, sexo etc.

Hipotireoidismo de adulto: Além das formas já mencionadas verifica-se ainda outra especial nos individuos que apresentam desenvolvimento rompleto. Nestes casos a insuficiencia tireoidiana é atenuada, e revela se á observação clinica por certo numero de sinais que a identifica de algum modo com a sindrome descrita por HERTOGHE com a denominação de hipotireoidia cronica benigna. Em regra, os individuos que, nacidos nas zonas contaminadas pelo Trypanosoma cruzi, puderam atravessar todo o periodo de desenvolvimento organico sem que perturbações funcionaes os condusissem a um dos tipos, infantilismo ou cretinismo, trazem sinais de funcionamento deficiente do orgam tireoidiano, que thes dão cunho particular de decadencia fisica, senilidade, precoce, etc. Esta condição morbida é mais acentuada nas mulheres, nas quais as fortes exijencias da vida sexual tornam de maior vulto o deficit endocrinico.

Taes hipotireoidianos mostram cabeleira rarefeita, a dentadura arruinada por carie, a péle palida, disqueratosica e enjelha$\mathrm{da}$, as funções geralmente entorpecidas. A hipotonia funcional torna-os lentos, preguicosos e pouco aptos para o trabalho prolongado, estado este frequentemente agravado pela miocardite cronica especifica com insuficiencia cardiaca consecutiva de que acabam geralmente por sucumbir.

No que respeita á etiolojia, os dados existentes não permitem afirmar com segu- 
rança se este estado morbido resulta de infeção unica contraida nos primeiros tempos da vida. A noção epidemiolojica estabelecida de que os naturais das rejiões infetadas são fatalmente expostos á ação inoculadora das triatomas desde que nacem e por outro lado a demonstração experimental, já feita de ser a molestia de CHAGAS imunisante, autorizariam a admitir esta hipotese para todos os casos, se houvesse certeza de que a imunidade assim adquirida fosse definitiva. Esta conjetura não está confirmada, não se pode portanto, afastar a possibilidade de infeções pos* teriores repetidas, consequentemente benignas que entretendo as lesões da glandula tireoide estabeleçam a permanencia do processo distrofico consecutivo, de evolução tambem benigna, aliás menos benigna do que o processo similar de HERTOGHE. Os incidentes agudos e suij-agudos acompanhados de reação febril, que algumas vezes se observam em casos cronicos da tripanosomiase devem constituir prova decisiva da possibilidade da reinfeção, se a orijem tripanosomica desses acidentes, atualmente admissivel por exclusão, tiver, como é de esperar, verificação parasitolojica positiva.

Tambem em relação á etiolojia, deve ser acentuada a suposição de que esta sindrorıe não é a expressão de infrção presente ou em atividade, e sim uma de suas consequencias mais ou menos remota, uma manifestação metatripanosomica, tendo para a tripanosomiase a mesma dependencia que, para a sifilis, têm certos estadios tardios, por isso chamados indiretos ou parasifiliticos, entre os quaes podem ser contados a arterio-esclerose e o infantilismo. Essa suposição, que é tambem estensivel ás outras formas das distrofias tireoidianas acima enumeradas, resulta da impossibilidade até agora havida de fazer-se o diagnostico propriamente parasitolojico nos hipotireoidianos das referidas categorias. Tal impossibilidade, porém, não pode ser considerada como definitiva, faltando para isso investigações bastante numerosas e sistematisadas, que ainda não puderam ser realisadas.
Borio: Comquanto fora dos limites desta dissertação o estudo do bocio endemico brasileiro, algumas referencias a respeito tornam-se necessarias pela circumstancia de ser ele elemento associado á endemia hipotireoidiana.

De fato, ha na distribuição geografica destas duas manifestaçõas morbidas coincidencia perfeita, que tem sido confirmada por todas as investigações feitas até o presente. Além disso, o bocio figura frequentemente nas proprias sindromes hipotireoidianas como sinal anatomico de grande evidencia. Esta associação geografica e individual já por si impõe a convição de etiolojia identica, que, em tal condição terá tambem a seu favor todos os argumentos apresentados anteriormente para demonstrar a orijem tripanosomica da endemia hipotireoidiana.

Destes argumentos resulta: que a agua, como veiculadora de ajentes infeciosos ou toxicos e outras infeções de carater endemico existentes nas rejiões devastadas pela molestia de CHAGAS, não pode ter, no caso, papel etiolojico; que só nas localidades e domicilios infestados pelas triatomas, hospedeiras do Trypanosoma cruzi, se verifica a presença do bocio; que as pessoas estranhas á rejião e que nela passam a residir ficam indenes do bocio, pondo-se ao abrigo da ação infetante do hematofago transmissor, embora beba da agua suposta bocijena $e$ sujeitas ás outras infeções ai reinantes.

$\mathrm{Ha}$, porém, uma prova que por sua importar.cia merece menção á parte: é a lesão infalivel da glandula tireoide pelo processo infecioso, iniciada quasi sempre na primeira infancia quando este ultimo se manifesta sob a forma aguda. Tal lesâo, que pode persistir ou ser entretida por novos ataques do protozoario, se carateriza pela destruição de celulas glandulares, quer pela ação direta deste parasito quer pela hiperplasia reacionaria do orgam, revelada clinicamente pela infiltração mixedematosa e outros sinais da hipofunção. Dado o forte poder de proliferação do epitelio tireoidiano, as partes glandulares não atinjidas pelo ajente infecioso necessariamente 
reajirão para suprir o deficit funcional e essa reação traduzir-se-á naturalmente pela multiplicação dos elementos epiteliaes, dando lugar a crecimento parenquimatoso que é a carateristica anatomica do bocio inicial e da juventude (bocio parenquimatoso). $\mathrm{Na}$ puberdade e nas mulheres durante a gravidez, a superatividade glandular propria dessas epocas exacerba a tumefação da tireoide, razão pela qual os doentes fazem geraimente datar dai o inicio do tumor tireoidiano. Nestes periodos começam, de ordinario, as formações cisticas que parecem resultar da destruição das paredes foliculares pelo aumento e provavel retenção de coloide (boclo coloidal, cistico ou difuso).

Assim considurado, o bocio será manifestação da tripanosomiase, de carater inflamatorio e reacionario, tendo evolução lenta e só tardiamente atinje a desenvolvimento anatomico completo. Tal concepção patojenica é tambem baseada nas observaçōes clinicas referentes ao modo pelo qual $o$ bocio se manifesta inicialmente nos individuos estranhos á rejião da endemia e que nela contraem essa afeção. Nesses individuos se tem notado verdadeira inflamação acompanhada de dôr e reação febril (observações de CHAGAS), ás quaes se segue o auments) de volume permanente.

Estes fatos não devem, entretanto, excluir a possibilidade de serem os proprios casos antigos resultantes diretos da infeção com a presença do protozoario no tecido glandular. Os estudos feitos por GASPAR VIANNA assinalam em doentes cronicos da molestia de CHAGAS a existencia na tireoide, ao lado das alterações proprias da dejeneração estrumosa, de fócos inflainatorios muito pronunciados em alguns pontos do orgam. Estes fócos, que a literatura medica não refere para o bocio de outros paizes, indicam forçosamente reação contra algum ajente morbido instalado no local visado pelo afluxo reacionario e constitue, por isso, indicio a favor da suposta função bocijena do Trypanosoma cruzi. Investigaçōes histo-patolojicas mais minuciosas e em numero suficiente, deverão confirmar esta asserção.
No ponto de vista epidemiolojico deven ser tomados em consideração certos elementos, que se apresentam como sendo de grande importancia para a classificação nosolojica das sindromes tireoidianas que acabamos de enumerar.

Estes elementos são a endemicidade destas mesmas sindromes e sua assuciação ao bocio endemico e a certas perturbações do aparelho auditivo, caraterizadas por diminuição da função, indo até a surdez completa.

Taes perturbações carecem ainda de estudos que venham esclarecer sua patojenia e a locálisação das lesões responsaveis. Conjenitas ou adquiridas desde a mais tenra infancia, elas, tanto podem exprimir alterações centraes como perifericas, ser de natureza dejenerativa consecutivas á insuficiencia tereoidiana, como resultantes da presença do protozoario no centro e nas vias nervosas da audição. Desse modo o mutismo, que as acompanha, deve ser atribuido á ausencia da audição geral, isto é, considerado como surdi-mudez comum. Em alguns casos, póde ele, talvez, traduzir a existencia de verdadeira afasia total por lesão dos centros da compreensão e da expressão da lirguajem. A diferenciação aqui é algumas vezes dificil, porquanto em muitos doentes as lesões cerebraes concomitantes reveladas por sintomas de diplejia, etc. , mostram a possibildade do comprometimento dos referidos centros, e purtanto, da existencia da afasia em suas modalidades. Serão, assim individuos que se tornam afasicos na epoca em que se inicia o funcionamento da linguajem e que, portanto, se acham em condições muito aproximadas das que caraterizam a afasia conjenita. A verificação destes fatos merece a atenção dos especialistas.

Qualquer que seja, porém, a solução dada a este problema, ela não deixará de confirmar a frequencia, nas zonas dominadas pela molestia de CHAGAS, de perturbações auditivas, reveladas pela surdez e a surdi-mudez, em varios gráus de intensidade, aparecendo com o carater de endemicidade e em extensão territorial identica ás do bocio e da propria tripariosomiase de CHAGAS. 
Assim sendo, as sindromes distroficas a que nos referimos, seriam justamente classificadas como cretinismo endemico. Este, geralmente considerado pelos patolojistas como estado morbido que se verifica sempre ao lado do bocio e da surdi-mudez, constitue com estes ultimos a dejeneração cretinica. Elas têm, além disso, para tal identificação, sua patojenia e os sintomas essenciaes do cretinismo que constituem a chamada triada de EWALD: as perturbações do desenvolvimento osseo, as alterações psiquicas e as alteraföes carateristicas paıa o lado da pele, sempre presente na generalidade dos casos, embora muitas vezes se apresente sob forma atenuada e incompleta. Deve-se, entretanto, acentuar, aqui, a intervenção de outros fatores que as diferenciam de certo modo do verdadeiro cretinismo endemico e autorizam a classificalas, antes como modalidades de entidade morbida que se poderá chamar de hipotireoidismo endemico adquirido. Taes fatores, já em parte mencionados no correr deste trabalho, se expressam nos seguintes dados, que parecem suficientemente positivos:

A evolução cronica e benigna observada na generalidade das sindromes, entre as quaes se notam frecuentemente formas incompletas, inicia-se depois de curto periodo de desenvolvimento normal.

A epidemiolojia fornece a noção de serem elas geralmente consecutivas á infeção (que no caso é a tripanosomiase) contraida em epoca limitada aos primeiros anos da infancia; a intensidade dos sinais morbidos parece depender da idade mais ou menos avanfada em que começou o processo distrofico.

O papel da herança, nos parece muito secundario; ha mesmo exemplos de serem os antecedentes hipotireoidianos muito apagados ou nulos.

\section{Outras distrofias.}

As pesquizas histo-patolojicas têm demonstrado que o Trypanosoma cruzi se localiza irequentemente em certas grandulas de secreção interna. No homcm, ell casos agudo 3 ou cronicos, assim como em animaes infetados experimentalmente, poude ser verificada muitas vezes a invasão desses organs pelo protozoario, determinando lesōes que ordinariamente produzem estado mais ou menos acentuado de hipofunção. Assim acontece, pondo de lado a tireoide, a que já nos referimos, com as capsulas supra-renaes, d hipofise e as glandulas genitaes (ovarios e testiculos), etc. . Nestas condições, as perturbações funcionaes resultantes de taes lesões, atendendo ao papel que, no metabolismo exercem esses mesmos organs, deveriam orijinar, tambem frequentemente, estados distroficos. Teoricamente a dedução impõe-se. $\mathrm{Na}$ pratica, porém, os fatos não se realizam desse modo, pois que nossa observação não rejista casos que se possam classificar entre os tipos conhecidos $\mathrm{c}$ bem individualizados das sindromes distroficas atribuiveis ás referidas alterações glandulares.

A explicação deste desacordo parece dever ser procurada na particularidade de efctuar-se quasi sempre o ataque infecioso nos primeiros tempos da infancia. As desordens da função tireoidiana, consecutivas a esse ataque, dominam dai por deante todo o desenvolvimento somatico e psiquico do doente, de modo que os sinaes de lesão dos outros organs endocrinicos ficam, por assim dizer, mascarados pelas manifestaçōes da insuficiencia tireoidiana inicial ou se apresentam mais ou menos atenuados, porém reconheciveis.

Deve concorrer tambem para isso a circumstancia admissivel de serem geralmente de pouca intensidade as lesões existentes, sendo em parte compensadas por esforço do proprio tecido atacado ou pelas correlações funcionaes dos organs similares ou eventuaes deficiencias resultantes dessas lesões.

Não obstante, se as alterações locaes das glandulas de seçeção interna, de frequencia incontestavel, não são de ordem a produzirem processos distroficos, que desviem o desenvolvimento geral dos doentes, elas são muitas vezes demonstraveis por sinaes varios no conjunto sintomatico geral da tripanosomiase. Estes sinaes podem resultar da hiperfunção 
glandular, mas, em regra, dada a natureza das lesões eapecificas, traduzem insuficiencia funcional do orgam. Apresentam-se sob o aspeto de verdadeiras sindromes de hiper ou hipofunção, algumas vezes com manifestações distroficas parciaes ou localisadas, que afetam determinados organs ou sistemas e dão feição especial a certas formas clinicas da molestia. A hiperfunção se verifica para o lado da tireoide nos portadores de bocio e em muitas formas da tripanosomiase parece ser sempre fato intercurrente e transitorio, que indica esforço de compensação. Não raramente se descobre, em hipotireoidianos francos, episodios dessa natureza, caraterizados por taquicardia, tremores, excitação, diarréa, oliıar brilhante etc., algumas vezes com aumento de temperatura e exoftalmia. Estes episodios desaparecem espontaneamente ou sob a ação terapeutica; ás vezes, persistem durante tempo mais ou menos longo, outras vezes manifestam-se intermitentemente, dando logar a sintomatolojia ocilante de verdadeira instabilidade tireoidiana. $O$ hiperjenitalismo é tambem observado nas zonas da endemia de CHAGAS, e se manifesta por varios sinaes, cuja paı́ojenia merece ser esclarecida. A menstruação precoce é um desses sinais, sendo que alguns casos desta especie se referem a individuos na primeira infancia infetados pela tripanosomiase (CHAGAS). Outros dizem respeito a hipotireoidianos, nos quaes se verifica o aparecimento da puberdade, o desenvolvimento anatomico pronunciado, ás vezes mesmo exajerado, dos organs sexuaes externos, das mamas, emquanto que outros caracteres sexuaes, o sistema piloso, o crecimento, a intelijencia etc. pouca alteração apresentam, mantendo-se em estado infantil. Deve-se notar que nestes casos o hipotireoidismo, evolvendo desde $o$ inicio do desenvolvimento individual, deveria determinar, como é de regra, hipoplasia genital e, se não admite um desenvolvimento normal, muito menos a referida condição hiperplastica ou de fúncionamento precoce. Estes fatos, não parecem ligados por simples compensação glandular á hipofunção tireoidiana existente. Tratam-se de individuos afetados pela tripanosomiase, cujo ajente, como é sabido, direta ou indiretamente por ação toxica, costuma atacar os organs em questão, de modo que o hiperjenitalismo pode ser muitas vezes o resultado de reação contra $o$ ataque direto do protozoario.

Os exames radiograficos revelaram aumento de volume da hipofise nos casos de hipotireoidismo infantil e de infantilismo, mas aqui a alteração anatomica, da qual aliás, nunca pudemos descobrir desordens funcionaes correspondentes, é explícavel pelas correlações endocrinicas desta glandula com a tireoide, devendic ser encarada como hipertrofia de compensação. O mesmo pode ser afirmado em relação ás formas de hiperjenitalismo, caraterizadas por menorrajias e pela polijestação, comumente observadas no hipotireoidismo cronico benigno do adulto. Taes perturbações são, de fato, assinaladas pelos especialistas no assunto como dependentes da insuficiencia tireoidiana.

Em relação aos sistemas supra-renaes, nossas observações dizem respeito somente ao hipofuncionamento. Os sinaes do hipo-epinefrismo são encontrados com certa frequencia nos afetados pela molestia de CHAGAS, em gráus variados de intensidade, e podem concorrer para a formação de verdadeiras sindromes pluriglandulares pelo fato de sua coexistencia com alterações tireoidianas ou endocrinicas de outra natureza.

Nos estados de hipotireoidismo, anteriormente descritos, é admissivel a cooperação das capsulas suprarenaes no aparecimento dumas tantas fórmas de astenia e emagrecimento, de acentuação notavel, assim como na reabsorpção da infiltração mixedematosa e na constituição do tipo magro e senil de alguns infantis, não obstante a carencia da verificação histo-patolojica nos casos singulares.

Em suas fórmas com melhor caraterização clinica, a insuficiencia suprarenal se manifesta, porém, por conjunto sintomatico que reproduz de algum modo o quadro da molestia de ADDISON. Nestes casos, verificados quasi sempre no adulto, notam-se, ao lado de outras manifestações da tripanosomiase, astenia intensa, dôres abdominaes vagas, 
lombares e epigastricas, perturbações dijestivas, pigmentação difusa da pele, como a coloração especial de bronze despolido mais acentuada nas partes descobertas e manchas pigmentares nas mucosas, etc., indicando a alteração epinefritica. Aqui, entretanto, a evolução morbida parece não se fazer como na verdadeira molestia de $A D D I S O N$, com $o$ cunho de extrema malignidade e o exito fatal que a distinguem. Pelo menos, os casos de morte que tivemos ocasião de observar, foram devidos á asistolia por miocardite especifica concomitante, não havendo razões de ordem clinica, ou mesmo histolojica para se atribuir essa terminação ás alterações capsulares.

Relativamente ás outras glandulas de secreção interna não mencionadas acima, faltam elementos para individualizar clinicamente processos distroficos delas dependentes. Achamse nestas condições o timo, o pancreas e o figado, que, aliás, no homem, não costumam ser parasitados pelo Trypanosoma cruzi. $\mathrm{O}$ figado, porém, sofre alterações graves e constantes na molestia de CHAGAS, sobretudo em sua fórma aguda, em que ele se mostra muito aumentado de volume, doloroso e atacado de dejeneração gordurosa carateristica, da qual resultam perturbações funcionaes graves. Estas alterações, que parecem ter orijem toxica, podem subsistir nas fórmas cronicas de infeção, de modo a colocar esse orgam em estado mais ou menos permanente de insuficiencia.

A observação clinica rejisla ainda perturbações troficas numerosas determinadas por lesão parasitaria do sistema nervoso, acontecendo muitas vezes que o processo distrofico atinje o desenvolvimento geral, retardando-o na esfera psiquica, como no estado somatico. Pertencem a esta categoria os doentes afetados de diplejia cerebral, que apresentam gráus diversos de idiotia, com paralisias, atrofias musculares, deformações osseas, etc. . As distrofias osseas e musculares não oferecem, no ponto de vista clinico diferença das que são observadas nos casos similares de orijem não tripanosomica. No que respeita, porém, ás alterações musculares em geral, deve ser levada em conta a intervenção direta do protoziario que encontra nos musculos estriados um dós pontos preferidos para se localizar e, multiplicando-se, póde influir na produção de taes alterações.

Nos retardados, fisica e inteletualmente, quer se tratem de diplejicos, quer de hipotireoidianos, encontram-se, algumas vezes, sinaes de mongolismo. Admitido, como parece mais plausivel, que o fator etiolojico principal da idiotia mongoloide é a exaustação materna, quaesquer que sejam suas causas, não admira possam existir nas rejiões da endemia de CHAGAS, com alguma frequencia, afetados desta sindrome, desde que aí as condições geraes de vida são geralmente agravadas por causas diversas de depauperamento, entre as quaes figuram a deficiencia alimentar, a multijestação e com outras molestias a propria tripanosomiase, em coeficiente elevadissimo. Entretanto, a verificação deste estado morbido não pode ser feita sem se atender ao fato de alguns de seus sinaes de importancia, aqueles dos quaes resulta a facies propriamente mongolica, constituirem caracteres etni$\cos$ da população indijena. Por outro lado, ha a considerar que os casos observados foram de individuos nos quaes as alterações resultantes da insuficiencia tireoidiana e das lesões nervosas concomitantes deturparam acentuadamente a morfolojia do tipo mongolico. De taes circunstancias, resulta dificuldade evidente no diagnostico clinico, o que, á primeira vista, dá impressão de extrema raridade desta especie morbida.

Terminando estas considerações, devemos mencionar alguns estados distroficos localizados que, não obstante constituirem elementos das sindromes já referidas, merecem ser destacados pela frequencia com que se apresentam e mesmo por sua importancia clinica. Destes, uns têm patojenia tireoidiana e como tal, beneficiam da opoterapia espe" cifica. São deste numero, certas afeções cutaneas que têm por base alterações no mecanismo da queratinização e a hipertrofia da camada cornea ou, em outros termos, a para- 
queratose e a hiperqueratose. Clinicamente mais comum, revela-se por estado desEamativo que se localisa, de preferencia, nos membros inferiores e toma, ás vezes, intensidade insolita dando á péle, que se torna aspera e pergaminhada, verdadeiro aspeto de lixa. Outras vezes, o processo evolve, dando logar á formação de crostas e laminas corneas, podendo ter um fundo eczematisado ou edematoso. Assim se nota no couro cabeludo, onde as formações queratosicas englobam os cabelos, produzindo placas esbranquiçadas de falsa tinha, de aspeto amiantaceo. Entre as afeções cutaneas que têm por substractum anatorrico a hiperqueratose, verificam-se a queraiose pilar relativamente frequente, os estados ictiosicos ou ictiosiformes, mais raros, e a queratodermia das extremidades, de que observámos alguns casos bastante demonstrativos.

Taes manifestações distroficas, se nada apresentam de extraordinario como entidades clinicas, assumem aqui certa importancia pelo fato de terem suficientemente esclarecida sua patojenia, que a epidemiolojia e os resultados terapeuticos obtidos demonstram correr por conta de perturbações tireoidianas. Elas têm tambem como carateristica a qualidade de não serem conjenitas, qualidade verificada pela anamnese, que, por outro lado, acusa sempre a respetiva aquisição em epoca posterior ao nacimento.

Outra distrofia digna de menção, é a que se carateriza por exajero da pigmentação cutanea e pela pigmentação das mucosas: A hipercromia da pele se expressa não só por pigmentação difusa, de coloração bronzeada, assestando-se com mais intensidade nas partes descorbertas, face, pescoço e mãos, como, tambem, por manchas pigmentares diversas nas dobras naturaes do corpo, na face, nos pontos habitualmente sujeitos á compressão ou atritos, nas cicatrizes, etc. . Ela é tambem notada, nos casos mais acentuados nas mucosas bucal e ocular sob a fórma de manchas, ou estrias.

Consideradas superficialmente, essas atterações pigmentạres poderiam ser levadas á conta de simples acentuação do pigmen- to normal, já por si muito carregado, dos naturaes da rejião sob a ação particularmente intensa e prolongada que aí tem a luz solar e outros ajentes fisicos do meio. Exame mais minucioso, porém, verifica que sobre serem de intensidade fóra do comum, elas têm significação patolojica, e se manifestam sempre em individuos afetados da tripanosomiase de CHAGAS e com sinaes de insuficiencia suprarenal.

Resta referir as distrofias dentarias que podem ser classificadas entre os tipos morfolojicos já conhecidos. Manifestam-se por erosões variadas, sob a fórma de sulcos, excavações, etc. . , localizadas na corôa ou na extremidade livre dos dentes. Raras vezes a alteração vai até ao microdontismo ou ao amorfismo dentario e em alguns casos elas são dispostas de modo a produzirem fórmas semelhantes ás chamadas atrofias cuspidianas, entre as quaes a de dente de HUTCHINSON. Encontram-se, além disso, vicios de implantação, falhas etc. , não falando na permanencia dos dentes de leite e das caries, que são manifestações indubitavelmente consequentes ao hipotireoidismo.

A particularidade a rejistar é que estas distrofias apresentam semelharça com as que se verificam na sifilis e no raquitismo, considerados, aliás, como as causas mais frequentes de taes anomalias. Estas molestias, entretanto, näo parecem exercer qualquer função no aparecimento das distrofias em questão, pois, nas rejiões em que foram observadas, a sifilis é rara e o raquitismo, pode-se dizer, desconhecido. Parece evidente, diante dos resultados da observação clinica, que a tripanosomiase é seu fator etiolojico principal se não exclusivo, ajindo, no caso, por intermedio das lesões nervosas ou da insuficiencia tireoidiana.

A opinião de FLEICHMANN e outros de que a hipoplasia do esmalte dentario, de que resultam certos tipos de distrofias, é consequencia da hipofunção paratireoidiana, não tem aqui elementos de comprovação, entre eles a presença da tetania a que estas distrofias estão sempre associadas. 